\title{
A planned long term approach to patient management
}

\author{
V BINDER, MD
}

ABSTRACT: On the basis of experience running an outpatient clinic for inflammatory bowel disease (IBD) for more than 25 years we concluded that a long term follow-up regimen offers both therapeutic and scientific advantages. The management program is based on treatment, information and social/ psychological support, factors which are mutually dependent. In Copenhagen County, patients are offered lifelong affiliation with the IBD clinic, which means annual visits and easy access to treatment during recurrences. With this system, we have been able to conduct epidemiological studies on the incidence and prevalence of IBD in Copenhagen County. A systematic approach to clinical activity assessment is available during the course of the disease for the individual patients. We have found the economic and psychological costs for such a lifelong surveillance program in IBD to be more than outweighed by the benefits to patients and society. Can J Gastroenterol 1990;4(7):369-371

Key Words: Crohn's disease, Management, Prognosis, Ulcerative colitis

\section{Le traitement du patient: Approche planifiée à long terme}

RESUME: A titre de directeur d'une clinique externe traitant les maladies inflammatoires de l'intestin (MII), l'auteur s'appuie sur cette expérience de 25 ans et conclut que le suivi à long terme offre des avantages à la fois thérapeutiques et scientifiques. Le programme de sa clinique intègre le traitement, l'information et le soutien socio-psychologique - facteurs qui sont mutuellement dépendants. Dans le comté de Copenhague, les patients peuvent bénéficier toute leur vie des services de la clinique des MII; c'est-à-dire qu'ils peuvent passer des visites annuelles et qu'ils ont facilement accès aux soins en cas de récidives. Dans ce cadre, l'auteur a poursuivi des études épidémiologiques sur l'incidence et la prévalence des MII dans le comté de Copenhague. Chaque patient peut se prévaloir d'une évaluation clinique systématique de l'activité de sa maladie. L'auteur estime que les avantages d'un programme permanent de surveillance des MII surpassent de beaucoup les coûts économiques et psychologiques, tant pour le patient que pour la société.

Department of Medical Gastroenterology C, Herlev University Hospital, Herlev, Denmark Correspondence and reprints: DrV Binder, Department of Medical Gastroenterology C, Herlev University Hospital, DK 2730 Herlev, Denmark. Telephone 44535300 ext 3622, Fax 44535332
J N COPENHAGEN COUNTY, DENMARK, which comprises the outskirts of central Copenhagen with about 500,000 inhabitants, we have had the opportunity to run a specialized outpatient clinic for inflammatory bowel disease (IBD) patients at Herlev Hospital for more than 25 years. From the very beginning we have been aware of exceptional conditions: a regional patient group in a social welfare society in which to study the course and outcome of IBD when treated using carefully defined principles. I shall try to describe some of our experiences and the advantages of a planned, long term approach to treatment, both from the patient's point of view and from a scientific angle.

The primary goals of treatment of patients with IBD are, in order of priority: to secure survival, to reduce morbidity, and to obtain optimal quality of life despite the disease. Since time factors differ for each of these goals, the importance of a long term commitment to the patient is obvious.

The mainstay in the management of $\mathrm{IBD}$, as with other chronic diseases, is treatment, information and psychological and social support. These factors mutually influence one another. Optimal treatment cannot be obtained un- 
less the patient is compliant, which again implies both relevant information and the necessary social and psychological conditions to allow the patient to follow the treatment regimen prescribed. Similarly, even optimal medical treatment does not reach its full power unless the patient is confident and optimistic, which can be facilitated by relevant information and psychological support.

The basis for attaining the ideal goals of high survival, low morbidity and high quality of life must be, according to my experience, a current scientific approach to the disease. Controlled therapeutic trials and studies of prognostic indicators, risk factors and course of the disease are necessary prerequisites and should be combined with more basic pathogenetic and etiological research. Patients with serious chronic diseases will naturally look to research, and in our experience gladly participate in such studies.

The patient material from Copenhagen County comprises all patients diagnosed during the period 1962-87 and living in the region at the time of diagnosis. A total of 1161 patients with ulcerative colitis and 373 with Crohn's disease have been followed and treated according to a carefully defined treatment regimen.

The principles for follow-up have included affiliation with the IBD clinic, annual 'routine' visits independent of disease activity, and rapid or even immediate access to the clinic in flare-up. Frequency of visits moreover is determined according to the patient's clinical needs.

The usual treatment has been maintenance with sulphasalazine or 5. aminosalicylic acid preparations if tolerated, and short but immediate courses of glucocorticoid treatment for exacerbations. Substitution therapy with iron, minerals, salts and vitamins is currently considered according to blood analyses. Surgical therapy is considered in cases of medical failure, with special attention to the proper timing of possible surgical intervention.

At each visit to the outpatient clinic a preformed chart is filled in by the physician about symptoms and signs, body weight, working and social conditions, as well as previous treatment.

The charts are collected in a special folder for the patient and kept at the outpatient clinic. At the end of each year, an overall assessment is made for each patient on the basis of the information obtained, indicating the disease activity, the extent of disease in the gastrointestinal tract and whether the disease has followed an intermittent or continuous course over the year. These annual assessments, together with the treatment given, are then referred to the computer for later evaluation of the total patient group.

The clinical decision to refer patients to a specialized clinic with continuous follow-up is justified by the well known high relapse rate in both ulcerative colitis and Crohn's disease more than $90 \%$ will experience a clini$\mathrm{cal}$ relapse within 10 years. Immediate and relevant treatment in flare-up may prevent complications and minimize the length of illness for the patients over the years. It is important to realize that both patients and inexperienced medical professionals, including doctors, tend to underestimate the severity of clinical symptoms in IBD, leading to a risk of postponed initiation of treatment. It is therefore of great importance to guide the patients in tackling disease situations since, as always with chronic diseases, the patients in fact 'treat' themselves in the intervals between visits to the hospital or clinic. The medical profession has an obvious obligation to give necessary and relevant information. Such guidance is in itself a psychological support for the patient, which is normally sufficient combined with information on the optimistic prognostic data available for IBD.

In our clinic, very early in the disease course, patients with ulcerative colitis are told about the possible need for surgical intervention (colectomy). We try to convince them to look at the colectomy as an option, a 'light in the darkness', if medical treatment should fail, instead of looking at a possible operation as the sword of Damocles hanging over his or her head.

Similarly we inform the patients with Crohn's disease of the importance of rapid treatment in flare-ups and the possibility of limited surgical resection in the case of stenosis of a bowel seg. ment, to prevent development of fis. tulas either to other bowel segments or to the surface. In our experience, early operation in such cases minimizes the risk of later development of short bowel syndrome, since the uncomplicated resection is much more limited in length. From the very beginning patients are informed of this policy. We do not make a secret of the tendency towards recurrences, but patients understand and accept that even if an operation is no guarantee against new attacks, it can be preferable treatment. This open information, in our experience, helps patients to have confidence in the clinic and in our ability to cope with the disease in all its aspects.

Social support will depend on the policy of the local community, and we are obliged to know the existing possibilities for patients. Generally, in young patients, we stimulate and motivate them to educate themselves to their highest capability and desire, which will increase their working capacity even if the disease later should take a more serious course. In Denmark there is a law which offers additional financial support to students with chronic diseases. We have another law for patients with chronic diseases, offering public support to their employer from the first day off due to the disease, instead of only after five weeks' ab. sence. This clause can only be used in documented cases with many days lost due to sickness. In such cases the benefits are applied for by the patient him or herself to keep the employer economically indemnified.

Similarly it is important to know the cost of drug therapy and to choose, on behalf of the patients, the cheapest of the analogous preparations, since in chronic diseases drug expenses will al. most always be a heavy economic bur den on patients.

The general principles in patient management mentioned here are carried out in practice in our clinic in close connection with our scientific goals: to 
perform a prospective follow-up study concerning disease activity, complications, extent of disease, treatment and social condition, especially working capacity.

In ulcerative colitis we have demonstrated a survival of patients not significantly different from that of the general population. The colectomy rate is $10 \%$ in the year of diagnosis, decreasing in the following years to about $1 \%$ per year, resulting in cumulative colectomy rates of about $30 \%$ after 20 years with ulcerative colitis.

The cumulative colectomy rates are, for patients with pancolitis on their initial attack, $33 \%$ in the first year increasing to $56 \%$ after 20 years; for patients with substantial colitis initially, $20 \%$ within the first three years and $35 \%$ after 20 years. Among patients with distal colitis on their first attack, very few are operated on in the first year, but $18 \%$ will have a colectomy within the following 20 years.

In Crohn's disease the survival demonstrated was normal in the first 15 years.

The annual operation rates for limited intestinal resections are $33 \%$ in the year of diagnosis, 4 to $11 \%$ in the following four years, and from then on $3 \%$ per year, independent of whether the patient has had an operation before.

Cumulative operation rates were $42 \%$ after 10 years for one operation only, and $13 \%$ for two or more intestinal resections. Forty-five per cent of patients thus remained medically treated only within the first 10 years with Crohn's disease.
In our studies we have found that, excluding the first three years, about one-half of the patient group at any time will present without disease activity, whereas the individual patient will experience changes in disease activity over the years. Before we performed the study, we had an impression of a much higher percentage of patients with disease activity, suggesting that the patients we see often and with severe symptoms will weigh more in our memory than those we seldom see and where the symptoms give no cause for concern.

The working capacity in our patient group for patients with ulcerative colitis is, excluding the first few years, similar to that of the general population.

Among Crohn's disease patients a minority of about $15 \%$ become incapable of working within 10 to 15 years. Seventy-five per cent retain full working capacity.

The difficult question of quality of life has been analyzed by case control studies on random samples of the two patient groups, based on interviews regarding familial, social and professional conditions.

We found that both ulcerative colitis and Crohn's disease patients lived a normal family life, with no more familial troubles or sexual problems than their age- and sex-matched controls. The patients had a slightly lower number of children.

Social activity was expressed by a score. The ulcerative colitis and Crohn's disease patients did not differ from the healthy controls in social activity.
These examples of results from a planned long term program for patient management are directly useful in daily clinical education and support. Against the background of such studies, general conditions for IBD patients in terms of life insurance and for employment in public and private jobs have improved considerably, provided they can document regular follow-up and connection with a specialized clinic.

Similarly, our initial policy for cancer surveillance in ulcerative colitis with barium enema or colonoscopy every second year now seems more or less superfluous, since we found no excess in cancer occurrence in the patient group compared to that in the general population. These figures indicate that the undoubtedly increased risk of colon cancer is connected to that subsection of ulcerative colitis patients who in our treatment regimen are colectomized early in the disease course. This means that the patients, with less extensive and more easily treatable disease, do not have an increased cancer risk, and therefore do not need close surveillance with repeated colonoscopies.

In conclusion, we suggest that patients with Crohn's disease and ulcerative colitis will benefit from close follow-up in a specialized clinic to ensure the right treatment at the right time as well as the necessary education and psychological and social support. These qualities will be difficult to obtain outside of clinics because of the relative infrequency of the diseases. 


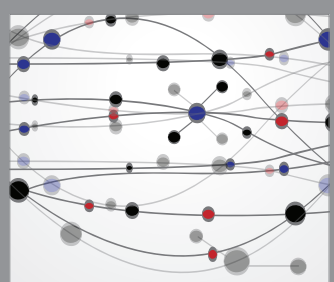

The Scientific World Journal
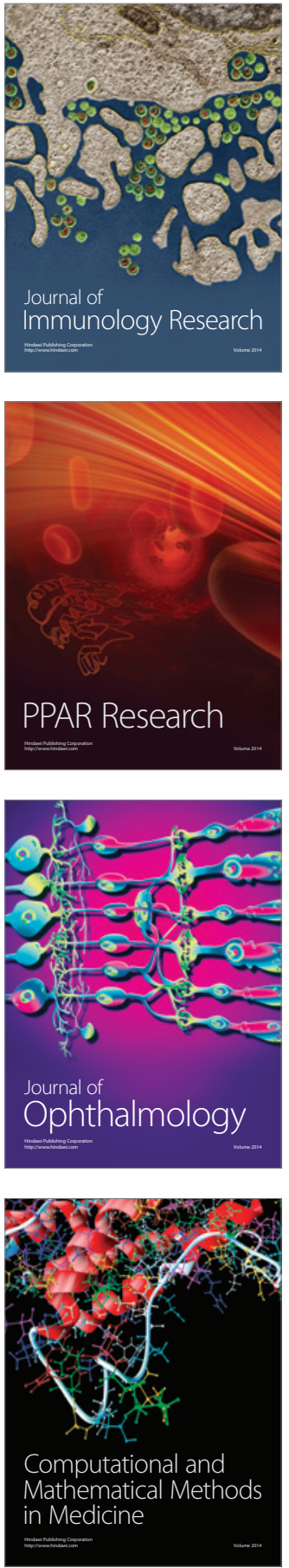

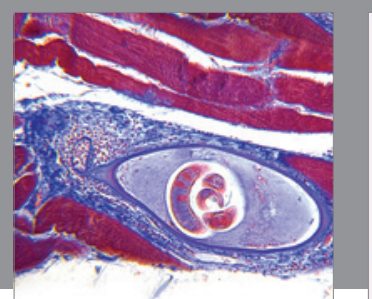

Gastroenterology Research and Practice

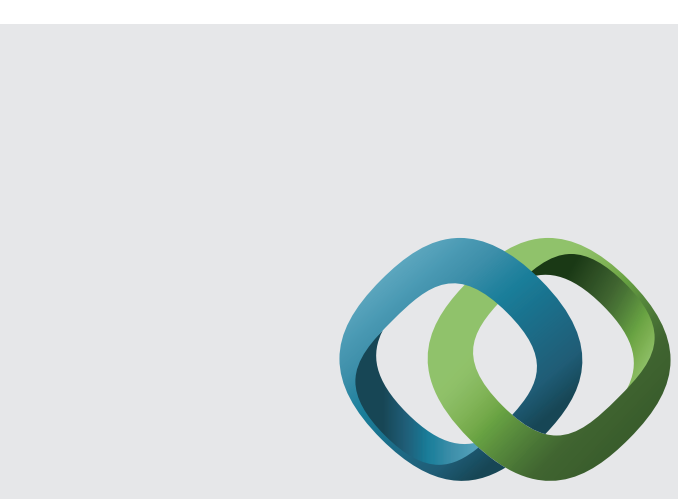

\section{Hindawi}

Submit your manuscripts at

http://www.hindawi.com
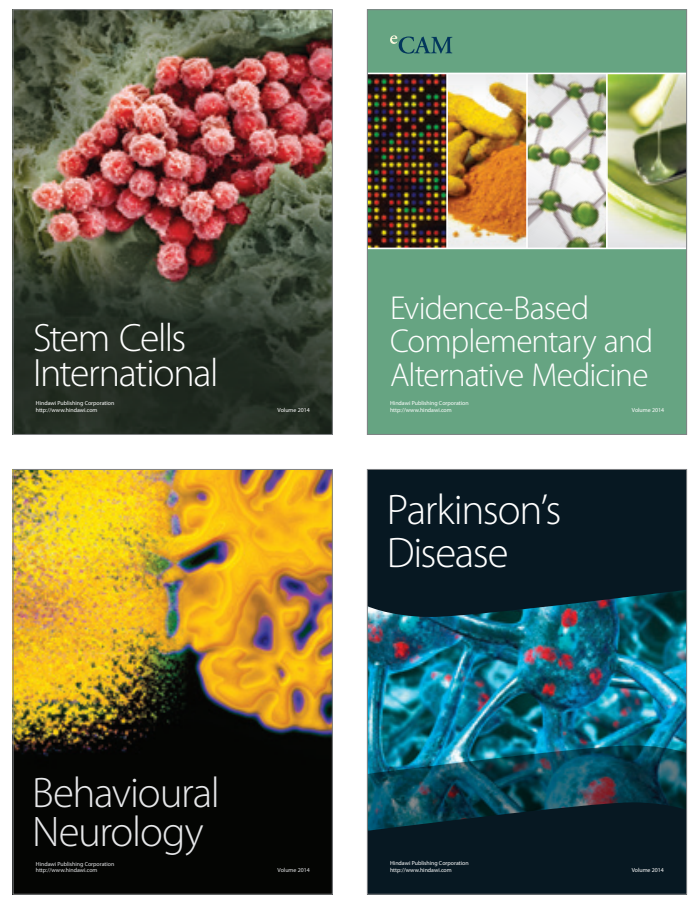
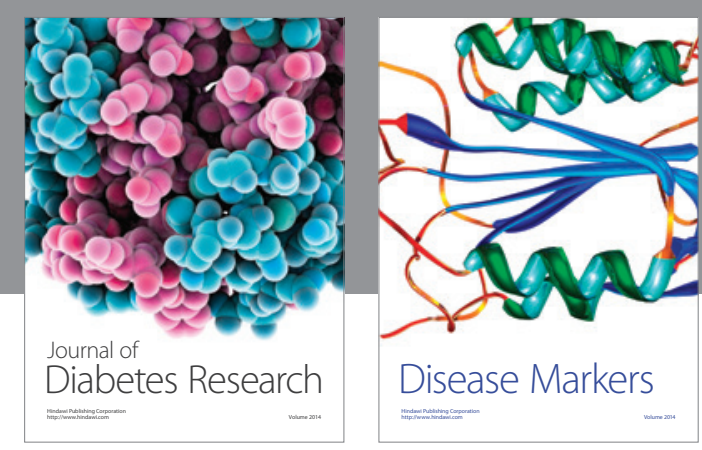

Disease Markers
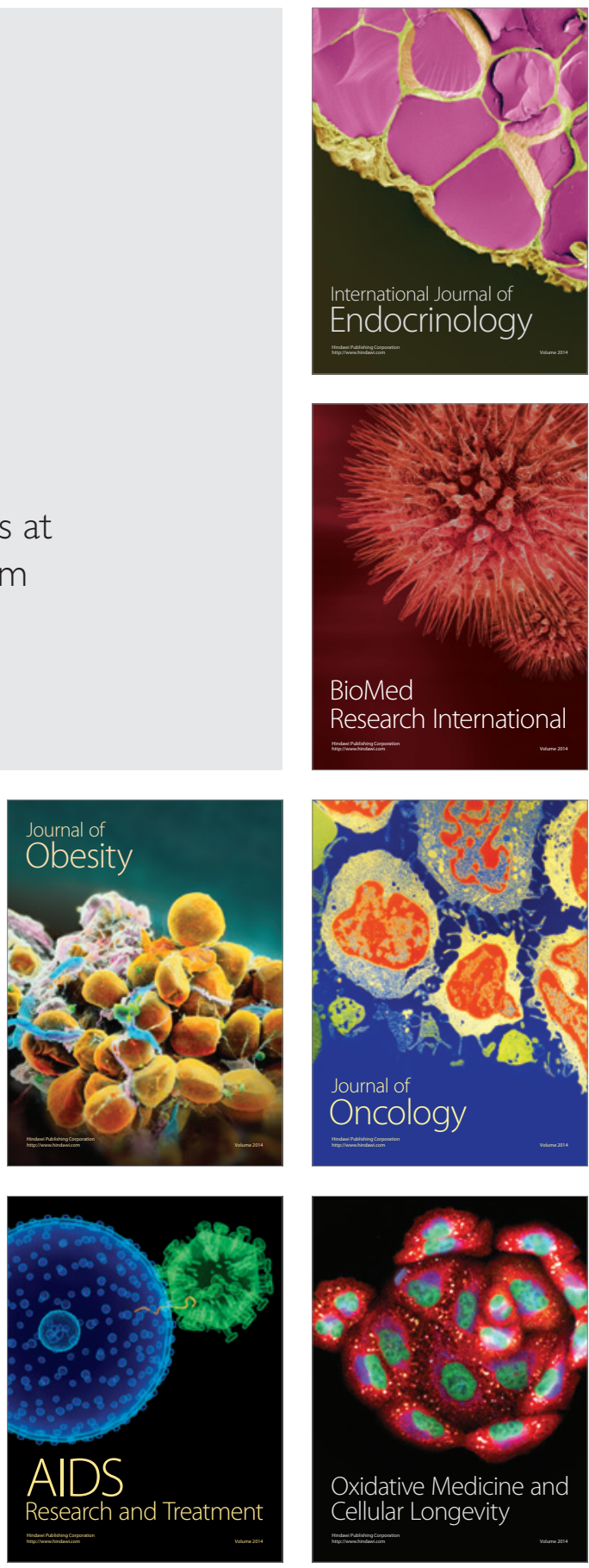